\title{
Forelimb Akinesia in the Rat Parkinson Model: Differential Effects of Dopamine Agonists and Nigral Transplants as Assessed by a New Stepping Test
}

\author{
M. Olsson, G. Nikkhah, ${ }^{a}$ C. Bentlage, and A. Björklund \\ Department of Medical Cell Research, University of Lund, S-223 62 Lund, Sweden
}

\begin{abstract}
Methods for the assessment of akinesia in the unilateral rat Parkinson model have so far been lacking. The experiments reported here evaluate the usefulness of a new "stepping test" to monitor forelimb akinesia in rats with unilateral 6-hydroxydopamine (6-OHDA) lesions of the mesencephalic dopamine (DA) system, and to assess the ability of DA-receptor agonists and fetal DA neuron transplants to reverse these deficits. The 6-OHDA lesion induced marked and long-lasting impairments in the initiation of stepping movements with the contralateral paw. Systemic injections of low doses (chosen to be subthreshold for induction of rotation) of the mixed D1 and D2 receptor agonist apomorphine, the D1-selective agonist SKF 38393, and to a lesser extent also the D2-selective agonist quinpirole were effective in reversing these deficits. Similar effects was seen after a subrotational dose of L-dopa, whereas amphetamine had no effect. Fetal nigral transplants, implanted as multiple deposits in the ipsilateral caudate-putamen and substantia nigra, restored initiation of stepping to a similar degree as the DA agonists. Nigral grafts placed in substantia nigra alone were also effective, although the improvement was less pronounced. Apomorphine, at a dose effective in the lesion-only animals, had no additive effect in the grafted rats, whereas amphetamine appeared to further improve stepping in the rats with intranigral transplants. Identical experiments were performed on skilled forelimb use in the so-called staircase test. Interestingly, neither the DA agonist drugs nor the nigral transplants had any effects on the lesion induced deficits in this more complex task. The results show that forelimb stepping is a highly useful test to monitor lesion-/and transplant-induced changes in forelimb akinesia, a behavioral parameter that may be analogous to limb akinesia and gait problems seen in patients with Parkinson's disease.
\end{abstract}

Key words: neural grafting, striatum, substantia nigra, paw reaching, apomorphine, L-dopa

\footnotetext{
Received Sept. 23, 1994; revised Nov. 17, 1994; accepted Dec. 7, 1994.

We thank Gertrude Stridsberg, Ulla Jarl, Kerstin Fogelström, and Sten Nilsson for expert technical assistance, and Siv Carlson for assistance in manuscript preparation. This study was supported by grants from the Swedish MRC (04X3874 ), the National Institutes of Health (NS-06701), and the Gorran Gustafsson Foundation. G.N. was supported by a grant from the Deutsche Forschungsgemeinschaft (DGF Ni 330/1-1).

Correspondence should he addressed to Martin Olsson, Department of Medical Cell Research, University of Lund, Biskopsgatan 5, S-223 62 Lund, Sweden.

a Present address: Neurosurgical Clinic, Norstadt Hospital, Haltenhoffstrasse 41, D-30167 Hannover, Germany.

Copyright (C) 1995 Society for Neuroscience $\quad 0270-6474 / 95 / 153863-13 \$ 05.00 / 0$
}

Rats with 6-hydroxydopamine (6-OHDA)-induced lesions of the nigrostriatal dopamine (DA) system develop neuropathological and neurochemical changes similar to those seen in patients with Parkinson's disease (PD). When such lesions are applied bilaterally, the animals exhibit a hypolocomotion syndrome that can be viewed as analogous to the akinesia in the human condition (see Dunnett and Robbins, 1992, for a recent review). However, in rats, bilateral complete lesions of the DA system are complicated by a profound eating and drinking deficit, and thus the lesioned animals can be maintained only by constant tube feeding. For this reason most experimental studies in rats have resorted to unilateral lesions that the animals tolerate very well.

Rats subjected to unilateral 6-OHDA lesions, on the other hand, exhibit more subtle motor deficits. The most pronounced changes are seen in drug-induced responses, such as amphetamine-/and apomorphine-induced turning, and have therefore become standard tools for quantitative functional assessment in the rat PD model. Although robust and easy to quantify, druginduced turning is a functional test that has an unclear relation to the symptomatology of human PD; the most relevant aspect of DA agonist-induced turning is probably that it provides a behavioral measure of striatal DA receptor supersensitivity and agonist-induced dyskinesia in the animal model.

Assessment of akinesia, which is a cardinal feature of PD, has so far been unsatisfactory in the unilateral rat PD model. Tests of sensorimotor orientation (Marshall and Teitelbaum, 1974; Dunnctt and Iversen, 1982) and so-called disengage behavior (Schallert and Hall, 1988) are commonly used to assess the ability of the rats to imitate motor responses, but they do not specifically test aspects of limb function. Skilled paw reaching (Whishaw et al., 1986; Montoya et al., 1991), on the other hand, is more complex and has an important motivational component that may complicate the interpretation of the results.

There is thus clearly a need for a wider repertoire of tests for changes in spontaneous, that is, non-drug-induced, motoric behavior in the unilateral PD model, in particular for the monitoring of limb akinesia. Schallert et al. (1992) have recently introduced a "stepping test" that is intended to pick up motor initiation deficits in the forelimbs, analogous to limb akinesia and gait problems in PD patients. The present study was designed to evaluate the usefulness of a modified version of this stepping test to monitor lesion- /and transplant-induced changes in forelimb akinesia, and to explore the sensitivity of this parameter to systemically administered DA receptor agonists. For comparison, a similar set of experiments was performed on skilled forelimb use in the paw-reaching test. 
Sequence of behavioral testing in Experiment 1

\begin{tabular}{|c|c|c|}
\hline \multirow{2}{*}{$\begin{array}{l}\text { Time points } \\
\text { (weeks) }\end{array}$} & \multicolumn{2}{|l|}{ Tests } \\
\hline & GROUP $1(n=18)$ & GROUP $2(n=19)$ \\
\hline 0 & T Stepping test pretraining (5d) & Paw-reaching test (4d) \\
\hline 1 & - Stepping test (3d) & \\
\hline 2 & 十 6-OHDA lesion $(n=8)$ & $6-$ OHDA lesion $(n=9)$ \\
\hline 4 & f Rotation, d-amph, $5 \mathrm{mg} / \mathrm{kg}$ i.p. & Rotation, d-amph \\
\hline 5 & - Stepping test (3d) & \\
\hline 6 & - Stepping test (3d) & \\
\hline 7 & - Stepping test (3d) & Paw-reaching test (4d) \\
\hline 8 & - Stepping test, apomorphine (1d) & Paw-reaching test, apomorphine ( $1 \mathrm{~d})$ \\
\hline 9 & + Stepping test, SKF 38393 (1d) & Paw-reaching test, SKF 38393 (1d) \\
\hline 10 & - Stepping test, quinpirole (1d) & Paw-reaching test, quinpirole (1d) \\
\hline 11 & † Stepping test, d-amph (1d) & \\
\hline 12 & - Stepping test, L-DOPA (1d) & \\
\hline 22 & - DA and NA biochemistry & \\
\hline
\end{tabular}

The drugs were given in the following doses: apomorphine $(0.0125 \mathrm{mg} / \mathrm{kg} \mathrm{s.C.})$, SKF 38393 ( $2 \mathrm{mg} / \mathrm{kg}$ i.p.), quinpirole $(0.05 \mathrm{mg} / \mathrm{kg}$ i.p.), d-amphetamine (0.05 $\mathrm{mg} / \mathrm{kg}$ i.p.) and L-DOPA ( $8 \mathrm{mg} / \mathrm{kg}$ i.p.)

Figure 1. Sequence of behavioral testing in experiment 1.

\section{Materials and Methods}

\section{Experimental design}

Experiment I comprised two groups of rats. One group $(n=18)$ was used to study the effect of a unilateral 6-OHDA lesion and DA agonist drugs on forelimb stepping. The sequence of testing, lesion, and drug treatment is given in Figure 1. The second group of rats $(n=19)$ was used to study the effect of lesion and drugs on skilled forelimb use, following the same experimental design as for the stepping test (right column in Fig. 1).

In Experiment 2 the stepping and paw-reaching tests were applied to 6-OHDA-lesioned animals transplanted with a cell suspension of fetal ventral mesencephalic (VM) tissue. The sequence of surgery, testing, and drug treatment is given in Figure 2. Twenty rats with a complete unilateral 6-OHDA lesion were pretrained on the stepping test, followed by transplantation of VM grafts into both the caudate-putamen (CPU) and substantia nigra (SN) $(n=8)$, or into SN alone $(n=4)$; a control group $(n=8)$ either received control transplants of fetal spinal cord or were left as lesion-only controls. The animals were retested on the stepping test at 12 and 24-25 weeks posttransplantation and the paw-reaching test was carried out for $5 \mathrm{~d}$ at 14 weeks after grafting. The rats were sacrificed and the brains were taken for TH immunohistochemistry at 39 weeks after grafting. The animals were also tested for rotational behavior, sensorimotor neglect, and disengage behavior. These data together with the results of the microscopic analysis, using in situ hybridization histochemistry, will be described separately (Bentlage et al., unpublished observations).

\section{Animals and 6-OHDA lesion surgery}

A total of 57 female Sprague-Dawley rats (BK Universal, Stockholm, Sweden), weighing $200-225 \mathrm{gm}$ at the beginning of the experiment, were used. The rats were maintained in a temperature-controlled environment under a $12 \mathrm{hr}$ light/dark cycle with free access to food and water when not in experimental sessions. In 38 of the rats two stereotaxic injections of 6-hydroxydopamine (6-OHDA-HBr; Sigma; 3.6 $\mu \mathrm{g} / \mu \mathrm{l}$ in $0.2 \mathrm{mg} / \mathrm{ml} \mathrm{L}$-ascorbate-saline) were performed into the right ascending mesostriatal dopamine pathway using a $10 \mu \mathrm{l}$ Hamilton syringe at the following coordinates (in $\mathrm{mm}$, with reference to bregma and dura): (1) $2.5 \mu \mathrm{l}$ at AP $-4.4, \mathrm{~L} \mathrm{1.2,} \mathrm{V} \mathrm{7.8,} \mathrm{tooth} \mathrm{bar} \mathrm{-2.4;} \mathrm{(2)} 3$ $\mu \mathrm{l}$ at $\mathrm{AP}-4.0, \mathrm{~L} 0.8, \mathrm{~V} 8.0$, tooth bar +3.4 . The injection rate was 1 $\mu \mathrm{l} / \mathrm{min}$ and the cannula was left in place for an additional $5 \mathrm{~min}$ before slowly being retracted.

\section{Rotational behavior}

Rotational behavior was assessed using automated rotometer bowls, as described by Ungerstedt and Arbuthnott (1970). Two weeks after 6OHDA lesion surgery, each rat was injected with $d$-amphetamine (5.0 $\mathrm{mg} / \mathrm{kg}$, i.p.) and their motor asymmetry was recorded for $90 \mathrm{~min}$. Only

\section{Sequence of behavioral testing in Experiment 2}

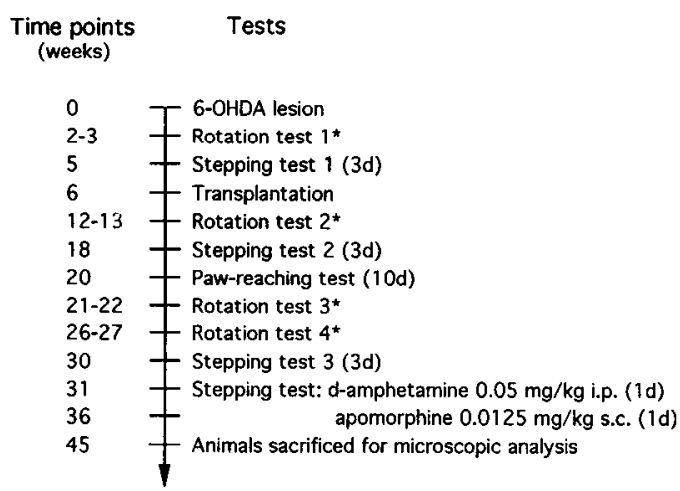

* In each rotation test rotation induced by d-amphetamine $(5 \mathrm{mg} / \mathrm{kg})$, apomorphine $(0.05 \mathrm{mg} / \mathrm{kg})$, SKF $38393(2 \mathrm{mg} / \mathrm{kg})$ and quinpirole $(0.5 \mathrm{mg} / \mathrm{kg})$ were studied ( 3 days interval between each test).

Figure 2. Sequence of behavioral testing in experiment 2.

rats exhibiting a rotation rate of at least seven full body turns/min ipsilateral to the lesion were included in the study. Rats receiving ventral mesencephalon (VM) transplants (experiment 2) were also tested for dopamine agonist-induced rotation (apomorphine, $0.05 \mathrm{mg} / \mathrm{kg}$, s.c.; SKF $38393,2 \mathrm{mg} / \mathrm{kg}$, i.p.; and quinpirole, $0.5 \mathrm{mg} / \mathrm{kg}$, i.p.) at different intervals postgrafting, as indicated in Figure 2.

\section{Stepping test}

Experimental setup. The tests monitoring initiation time, stepping time, and step length were performed on a wooden ramp with a length of 1.1 $\mathrm{m}$ connected to the rats' home cage (Fig. $3 A$ ). A smooth- surfaced table with a width of $0.9 \mathrm{~m}$ was used for the test measuring adjusting steps (Fig. $3 B-D$ ). All testing was performed during daytime.

Handling and training. During the first $3 \mathrm{~d}$ the rats were handled by the experimenter to become familiar with the experimenter's grip. During the subsequent $1-2 \mathrm{~d}$ the rats were trained to run spontaneously up the ramp to the home cage. Food deprivation and food reward in the home cage were found to be unnecessary.

The stepping test comprised two parts: first, the time to initiation of stepping by each forelimb, the step length, and the time required for the rat to cover a set distance along a ramp with each forelinnb; and second the initiation of adjusting steps by each limb when the animal was moved sideways along the bench surface. Each test (except the drug tests) consisted of two tests per day for 3 consecutive days, and the mean of the six subtests were calculated. The drug tests were administered during $1 \mathrm{~d}$ only.

Initiation time, stepping time, and step length. The rat was held by the experimenter with one hand fixing the hindlimbs and slightly raising the hind part above the surface. The other hand fixed the forelimb not to be monitored (Fig. 3). Time was measured until the rat initiated movement with the forelimb not fixed by the experimenter, using 180 sec as break off point. "Stepping time" was measured from initiation of movement until the rat reached the home cage; step length was calculated by dividing the length of the ramp by the number of steps required for the rat to run up the ramp. The sequence of testing was right paw testing followed by left paw testing, repeated twice.

Adjusting steps. The rat was held in the same position as described above with one paw touching the table, and was then moved slowly sideways ( $5 \mathrm{sec}$ for $0.9 \mathrm{~m}$ ) by the experimenter, first in the forehand and then in the backhand direction (Fig. 3). The number of adjusting steps was counted for both paws in the backhand and forehand directions of movement. The sequence of testing was right paw forehand and backhand adjusting stepping, followed hy left paw forehand and backhand directions. The test was repeated twice each day.

\section{Drug tests}

The following drugs were used: apomorphine $(0.0125 \mathrm{mg} / \mathrm{kg}$ in L-ascorbate-saline, s.c.), the D1-reseptor selective agonist SKF $38393(2 \mathrm{mg} / \mathrm{kg}$, i.p.), the D2-receptor selective agonist quinpirole $(0.05 \mathrm{mg} / \mathrm{kg}$, i.p. $)$, L3,4-dihydroxyphenylalanine (dopa)/carbidopa $(8 / 0.8 \mathrm{mg} / \mathrm{kg}$, i.p.), and $d$ - 

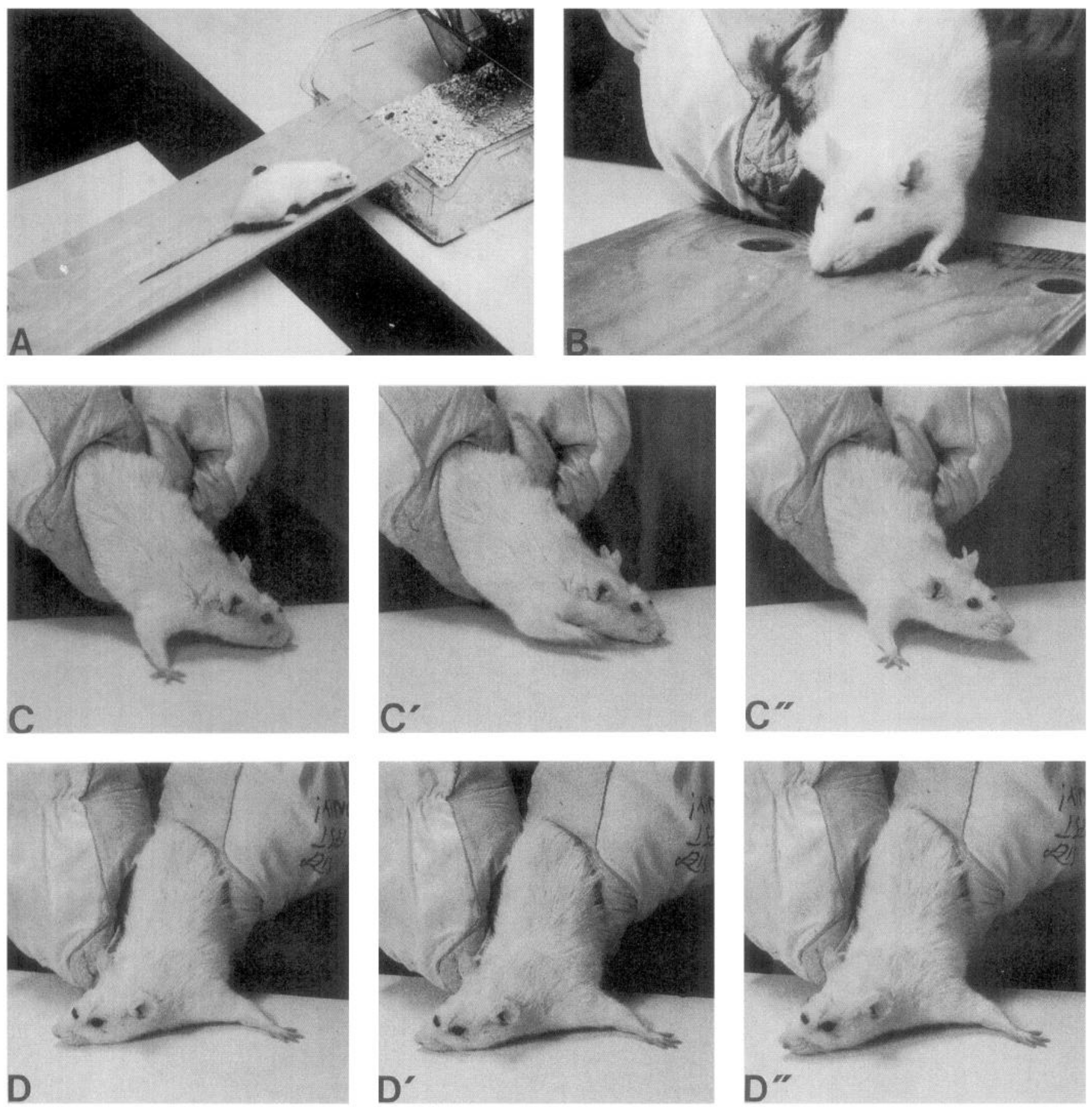

Figure 3. Elements of the stepping test. A, Arrangements of the wooden ramp, connected to the home cage, showing a rat during pretraining, during which the rat is allowed to run freely up the ramp to reach the home cage. $B$, Position of the rat in the assessment of initiation time. $C-C^{\prime \prime}$, Sequence of adjusting steps of the ipsilateral right paw in the forehand direction, of a rat lesioned with 6- OHDA on the right side. $D-D^{\prime \prime}$, Similar sequence of pictures in the test for adjusting steps of the left paw, contralateral to the lesion. Note that the contralateral paw is passively dragging when the rat is moved in the forehand direction, while the ipsilateral paw performs frequent stepping movements. For further details, see text.

amphetamine $(0.05 \mathrm{mg} / \mathrm{kg}$, i.p.). In experiment 1 the drug tests were performed with weekly intervals in the above-mentioned sequence. In experiment 2 the amphetamine and apomorphine tests were separated by 5 weeks. Each testing was performed for $1 \mathrm{~d}$ with every parameter monitored twice. The doses used were chosen on the basis of a pretest, such that for each drug the dose was set to be just below the level of induction of rotation. Testing was started 5 min following injection.

\section{Skilled forelimb use (paw reaching)}

A modified version of the staircase test described by Montoya et al. (1991) was used. For each test the animals were left in the test boxes for $15 \mathrm{~min}$. The double staircase was filled with $4 \times 10$ chow pellets (45 mg) on each side. After each test the number of pellets taken and the number of pellets eaten were counted separately. In experiment I the test was performed on a separate group of 10 normal and 9 unilaterally 6-OHDA-lesioned animals. After $3 \mathrm{~d}$ of food deprivation the animals were trained for $4 \mathrm{~d}$ prelesioning (data not shown), and then retested for $4 \mathrm{~d}$ at 3 weeks after the 6-OHDA lesion. The mean was calculated from the 4 test days. The animals were then tested with a single dose of apomorphine, SKF 38393 , and quinpirole, with $3 \mathrm{~d}$ intervals between each test. The same subrotational doses as for the step- 
Table 1. Coordinates used for implantation of VM transplants

Grafts into the striatum

Grafts into the substantia nigra

\begin{tabular}{|c|c|c|c|c|c|c|c|c|c|c|c|c|c|c|}
\hline \multirow[b]{2}{*}{$\mathrm{Tr}$} & & & \multirow[b]{2}{*}{6} & \multirow[b]{2}{*}{7} \\
\hline & 1 & 2 & 3 & 4 & 5 & 6 & 7 & 1 & 2 & 3 & 4 & 5 & & \\
\hline \multicolumn{15}{|l|}{ Anterior/posterior } \\
\hline to bregma & 1.8 & 1.5 & 1.5 & 0.5 & 0.5 & -0.5 & -1.5 & -5.9 & -5.9 & -6.4 & -6.4 & -6.9 & -6.9 & -7.4 \\
\hline Lateral & 1.5 & 2.2 & 3.4 & 2.5 & 4.0 & 4.2 & 4.5 & 1.6 & 2.2 & 1.6 & 2.2 & 1.6 & 2.2 & 1.9 \\
\hline \multirow[t]{3}{*}{ Ventral to dura mater } & 7.3 & 5.5 & 5.5 & 6.0 & 5.5 & 5.5 & 5.5 & 7.2 & 6.8 & 7.4 & 7.0 & 7.4 & 7.0 & 7.2 \\
\hline & 6.3 & 4.0 & 4.0 & 4.0 & 4.0 & 4.0 & 4.0 & 7.0 & 6.6 & 7.2 & 6.8 & 7.2 & 6.8 & 7.0 \\
\hline & & 3.0 & 3.0 & 3.0 & 3.0 & 3.0 & 3.0 & & & & & & & \\
\hline
\end{tabular}

Volume

$200 \mathrm{nl}$ each

$250 \mathrm{nl}$ each

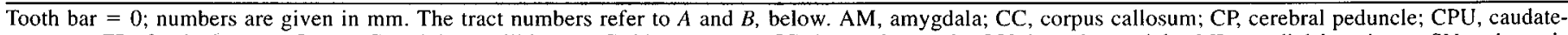

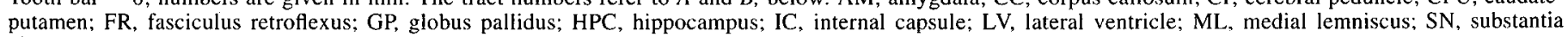
nigra (c, pars compacta; r, pars reticulata); SUT, subthalamic nucleus; VIII, third ventricle.

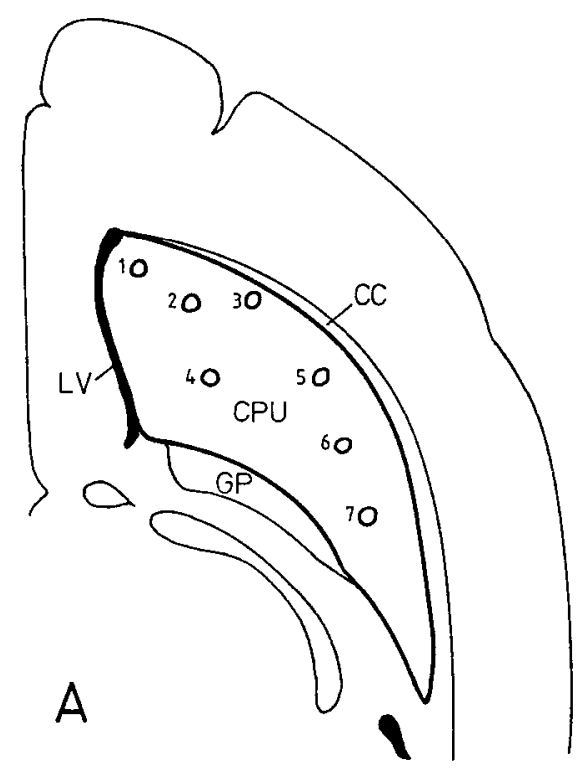

ping test were used. Testing started 5 min after injection of the drug. In experiment 2 the test was performed in a single session (without any pretraining) at 14-15 weeks after grafting. The animals were food deprived for $3 \mathrm{~d}$ and then tested for $10 \mathrm{~d}$ to train the animals up to asymptotic performance. The data given in Table 4 give the means of the 4 last test days.

\section{Transplantation surgery}

Transplantation followed the microtransplantation procedure of Nikkhah et al. (1993, 1994a,b). Ventral mesencephalon (VM) was dissected from E14 rat fetuses (crown-rump length, 11-12 mm) and collected in DMEM in an Eppendorf vial. The pieces were incubated in $0.1 \%$ trypsin (Worthington), $0.05 \%$ DNase (Sigma DN-25), and DMEM (GIBCO $041-01965$ ) at $37^{\circ} \mathrm{C}$ for $20 \mathrm{~min}$, followed by four rinses with $300-400$ $\mu l$ each of $0.05 \%$ DNase/DMEM. The mechanical dissociation of the tissue pieces were performed in $250 \mu \mathrm{l}$ of $0.05 \%$ DNase/DMEM by repeated tituration $(5-15 \times)$, starting with a $1 \mathrm{ml}$ Eppendorf pipetteman set at $200 \mu \mathrm{l}$ using a tip with opening size of $1 \mathrm{~mm}$. After the suspension became milky a $200 \mu$ l Eppendorf pipetteman was used with its smaller tip opening size $(0.5 \mathrm{~mm})$ for a second trituration $(5-15 \times)$ in order to achieve a complete single-cell suspension. The tissue was then centrifuged in the same Eppendorf tube at $600 \mathrm{rpm}$ for $5 \mathrm{~min}$, the supernatant carefully sucked off, and the pellet resuspended using a few triturations with the $200 \mu \mathrm{l}$ pipetteman in the final volume $(100-140 \mu \mathrm{l}$ of $0.05 \%$ DNase/DMEM). The viability and total cell number of this cell suspension was determined both prior to transplantation and posttransplanta-

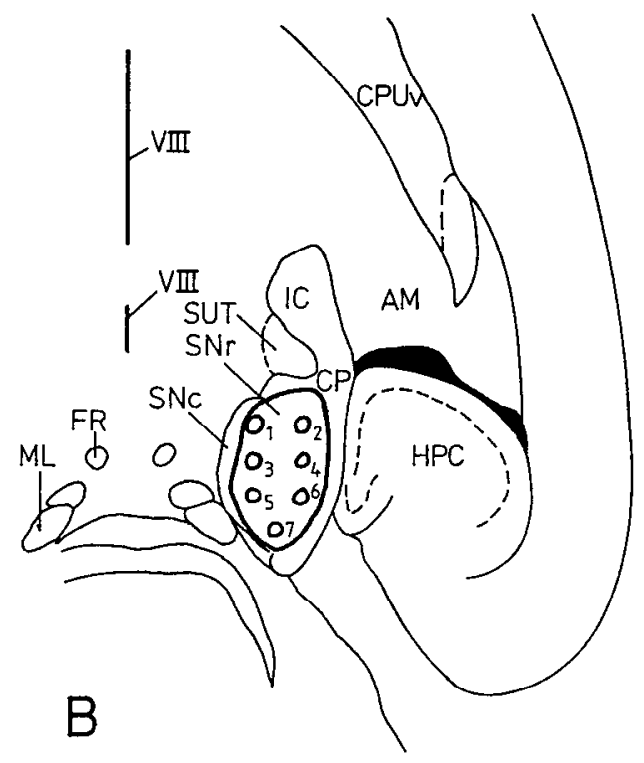

tion by the trypan blue dye exclusion method; the viability was $97 \%$ at both time points.

At 6 weeks after 6-OHDA lesion, micrografts were implanted using a $1 \mu$ l Hamilton microsyringe equipped with a glass capillary tip (micropipette) with an OD of 50-70 $\mu \mathrm{m}$. In eight rats (the $S N+C P U$ group) 14 deposits $(250 \mathrm{nl}$ each) were implanted into the lesioned substantia nigra, and 20 deposits $(200 \mathrm{nl}$ each) were implanted into the ipsilateral striatum according to Table 1. In four rats (the $S N$ group) grafts were placed in the substantia nigra only. Four of the eight 6-OHDA lesion control rats received control transplants of cell suspension prepared from E14 spinal cord, as above, and the remaining four were left as lesion-only controls. In the $\mathrm{SN}+\mathrm{CPU}$ group one rat died before the paw-reaching test and another animal died between the amphetamine and apomorphine tests. Two lesion-only rats died between the two drug tests.

\section{Dopamine (DA) and noradrenaline (NA) biochemistry (experiment 1)}

At 20 weeks postlesion the animals in experiment 1 were killed by decapitation under chloral hydrate anesthesia. The caudate-putamen, nucleus accumbens, and anteromedial frontal cortex were dissected bilaterally. The caudate-putamen was divided into a ventral and a dorsal portion. The dissected pieces were immediately frozen in liquid nitrogen. DA and NA levels were assayed according to the radioenzymatic method of Schmidt et al. (1982). 


\section{Microscopic analysis (experiment 2)}

At the end of testing the surviving rats in experiment 2 were processed, without perfusion fixation, for in situ hybridization histochemistry. These results will be reported in a parallel communication (Bentlage et al., unpublished observations). For the present study a separate series of cryostat sections from each animal were immersion fixed in $4 \%$ formalin and processed for immunohistochemistry using an antibody to tyrosine hydroxylase (TH; Pel-Freez) according to the procedure described previously (Nikkhah et al., 1994a).

\section{Statistical analysis}

Results are expressed as means \pm SEM. For statistical evaluation, the data were subjected to one-factor analysis of variance (ANOVA) and Fisher post hoc test. Statistical significance level was set at $p<0.05$.

\section{Results}

\section{Experiment 1. Effect of 6-OHDA lesions and DA} agonists on forelimb stepping and skilled paw use

\section{Stepping test}

After the 6-OHDA lesion the performance of the left paw (contralateral to the lesion) was significantly impaired compared to either the prelesion test or the intact controls. However, the magnitude of the lesion-induced impairment varied markedly among the different parameters of the stepping test. In addition, there was a general trend toward impaired performance in the paw ipsilateral to the 6-OHDA lesion.

Initiation time (Fig. 4). No significant difference was observed prelesion between the two groups. In the postlesion tests (performed 3-5 weeks after surgery; see Fig. 1) initiation of movement was substantially delayed in the contralateral (left) paw in all three tests (Fig. $4 B$ ). There was a trend toward a small $(0.5-$ $1 \mathrm{sec})$ delay in the initiation of movement also in the ipsilateral (right) paw; this effect reached significance in the first postlesion test (Fig. 4A). While the delay to initiate movement was $1-2 \mathrm{sec}$ for the ipsilateral paw, it was increased to 1-2 min on the affected contralateral side (note the difference in scale on the $y$ axis in Fig. $4 A, B)$. Initiation time for the contralateral paw was significantly reduced by all three DA agonists, but not by amphetamine. However, while apomorphine and the D1-receptor agonist SKF 38393 restored the initiation time to near-normal levels, a significant impairment remained after injection of the selective D2-receptor agonist quinpirole.

Stepping time (Fig. 5). The rats required significantly longer time to step up the ramp after the 6-OHDA lesion. This effect was seen with both the right and the left paw, but it was more pronounced when the rats were forced to use the left paw (Fig. $5 B$ ). Left paw performance was significantly improved by apomorphine, SKF 38393, and L-dopa, but not by quinpirole or amphetamine. In addition, SKF 38393 and amphetamine decreased stepping time for the right paw.

Step length (Fig. 6). A similar pattern of changes as for the stepping time was observed after the 6-OHDA lesion on the step length measure. Step length was significantly reduced on both sides but the effect was more marked for the left paw compared to both the prelesion test and the normal intact rats (Fig. 6A,B). There was a progressive increase in step length over the three postlesion test sessions in hoth the intact and the 6- OHDAlesioned animals with the right as well as the left paw. However, the significant difference between intact and 6-OHDA-lesioned animals remained throughout. In the lesioned rats only apomorphine treatment resulted in a significant increase in step length for the left paw, while the right paw performance was unaffected. The difference between the intact and 6-OHDA- lesioned
A

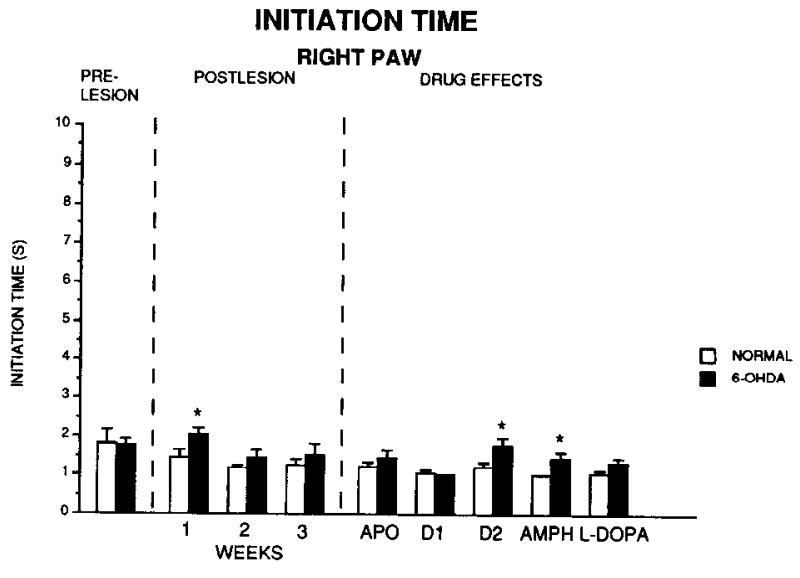

B

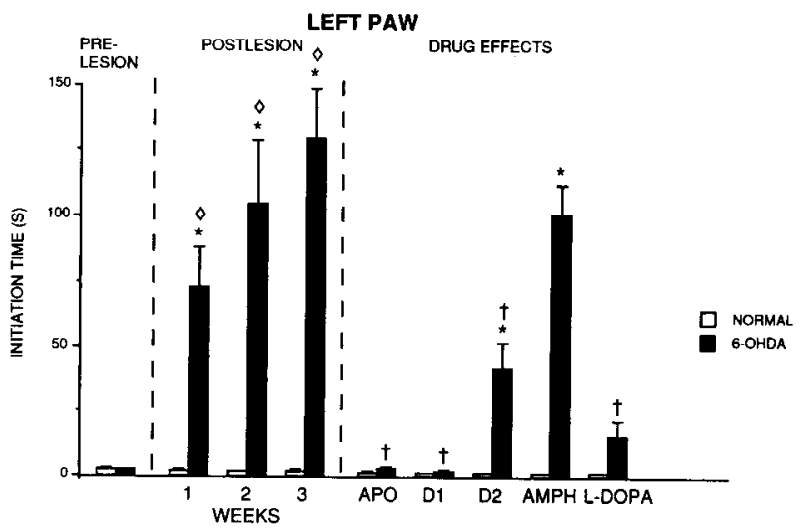

Figure 4. Experiment 1: initiation time for the right $(A)$ and left $(B)$ paw. The first postlesion test was performed 3 weeks after the 6-OHDA lesion and drug effects were analyzed at weekly intervals, starting 1 week after the last postlesion test, in the following sequence: apomorphine $(A P O)(0.0125 \mathrm{mg} / \mathrm{kg}$ in L-ascorbate-saline, s.c.), the D1-receptor agonist SKF $38393(D I)(2 \mathrm{mg} / \mathrm{kg}$, i.p.), the D2-receptor agonist quinpirole $(D 2)(0.05 \mathrm{mg} / \mathrm{kg}$, i.p.), $d$-amphetamine $(A M P H)(0.05 \mathrm{mg} / \mathrm{kg}$, i.p.), and L-dopa carbidopa ( $L-D O P A)(8 / 0.8 \mathrm{mg} / \mathrm{kg}$, i.p.). There was delayed left paw $(R)$ initiation in all postlesion testings whereas apomorphine, SKF 38393, and L-dopa reversed and quinpirole partly reversed these delays. ${ }^{*}$, significant difference between normal $(N=8)$ and 6- OHD $\wedge$ lesioned groups $(N-8)$; $\diamond$, significant difference compared to the prelesion testing; $\dagger$, significant difference compared to the third postlesion test; $p<0.05$, one-factor ANOVA with Fisher post hoc test. Error bars represent SEM.

animals remained significant for both the right and the left paw during all drug treatments.

Adjusting steps (Figs. 7, 8). This parameter was the one most profoundly affected by the 6-OHDA lesion. Thus, there was a highly significant impairment in left paw performance in both the backhand (Fig. $7 B$ ) and in the forehand direction (Fig. 8B), which resulted in a dragging paw when the rat was moved sideways by the experimenter (see Fig. 3). By contrast, right paw performance was unaffected (Figs. $7 A, 8 A$ ). With repeated testing, the intact animals showed a decline in the number of adjusting steps (from about 13 in the first pretest to about 10), suggesting some degree of habituation to the test. Apomorphine, SKF 38393, and L-dopa significantly improved the performance with the left paw, in both directions, whereas quinpirole and amphetamine were without effect. The most pronounced effect 
A

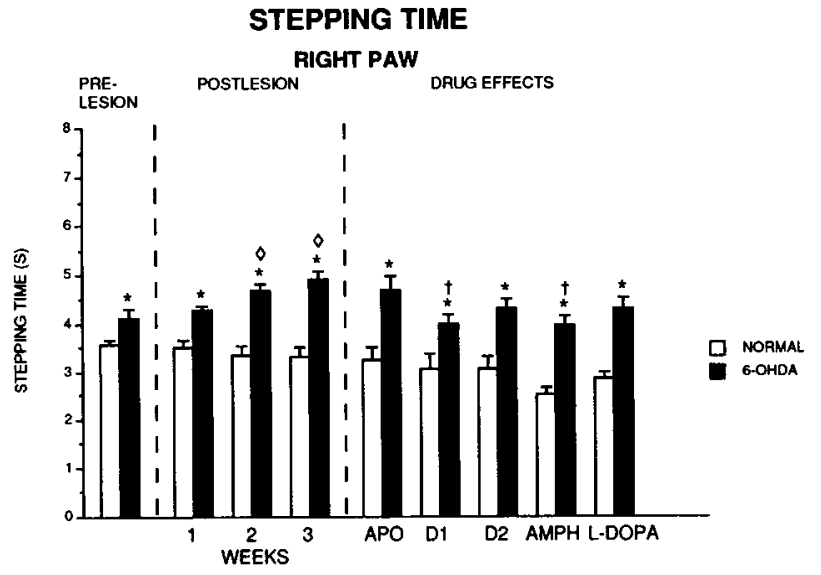

B

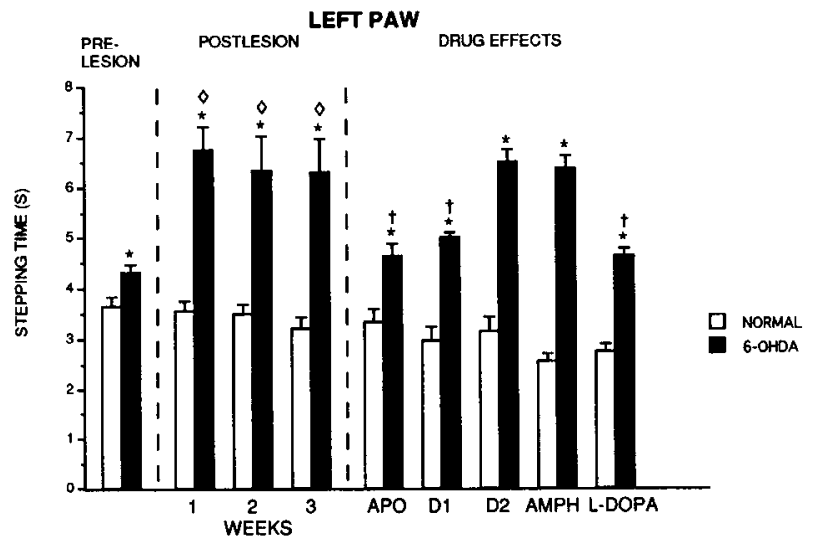

Figure 5. Experiment 1: stepping time for the right $(A)$ and the left (B) paw. The 6-OHDA-lesioned animals showed prolonged stepping time, with a more pronounced difference in left paw performance, and apomorphine, SKF 38393, and L-dopa partly reversed this impairment $(B)$. *, significant difference between normal $(N=8)$ and 6-OHDAlesioned groups $(n=8) ; \diamond$, significant difference compared to the prelesion test; $\dagger$, significant difference compared to the third postlesion test; $p<0.05$, one-factor ANOVA with Fisher post hoc test. Error bars represent SEM.

was seen after injection of SKF 38393, which restored the number of adjusting steps in the backhand direction to a level no longer different from that seen in the intact controls.

\section{Skilled forelimb use (paw reaching)}

As summarized in Table 2, the 6-OHDA lesion induced marked impairments in the performance of the left paw (contralateral to the lesion), which is consistent with previous data (Dunnett et al., 1987; Nikkhah et al., 1993). The deficit was significant when compared to both the intact controls $(p<0.05$ ), as well as to the ipsilateral right paw, and it was seen in both the number of pellets eaten (successfully retrieved pellets) and the number of pellets taken (touched but dropped) $(p<0.05)$. Some of the lesioned animals had scores of 0 , which excluded them from the percentage success measure, and thereby the right and left paw difference did not reach significance on this measure. The impairments were not reversed by any of the DA agonists. On the contrary, there was a general trend toward impaired performance during DA agonist treatment. In the intact rats, this effect reached significance after apomorphine (pellets eaten) and the
A

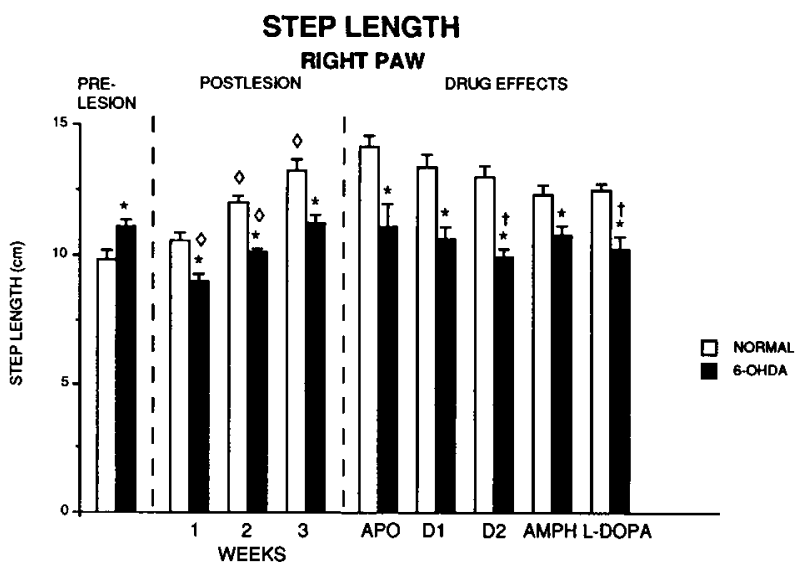

B

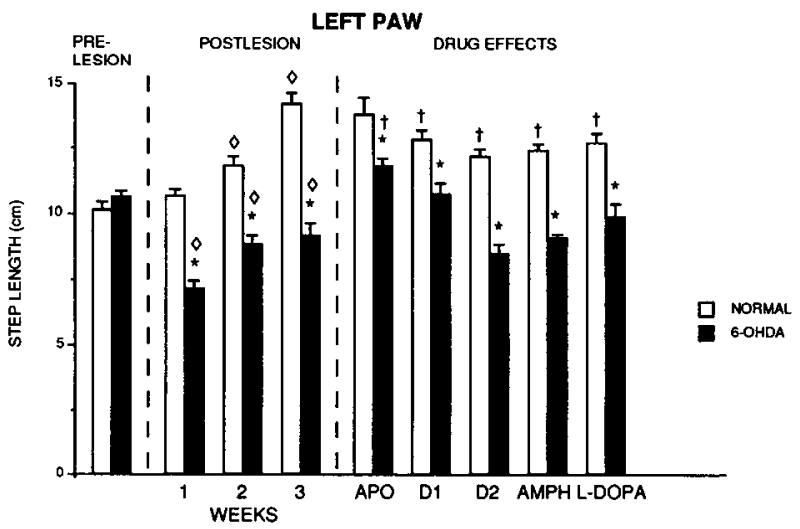

Figure 6. Fxperiment 1: step length for the right $(A)$ and left $(R)$ paw. Similar to the stepping time measure (Fig. 5) there was a 6-OHDAinduced effect, most pronounced in the left paw, and trends toward improved left paw performance after apomorphine, SKF 38393, and Ldopa. *, significant difference between normal $(n=8)$ and 6-OHDAlesioned groups $(n=8) ; \diamond$, significant difference compared to the prelesion test; $\uparrow$, significant difference compared to the third postlesion test; $p<0.05$, one-factor ANOVA with Fisher post hoc test. Error bars represent SEM.

D2-agonist quinpirole (all parameters). In the lesioned rats, further impairment was seen for the left paw after all three drugs and for the right paw after quinpirole.

\section{DA and NA biochemistry}

In the 6-OHDA-lesioned animals DA levels were reduced ipsilateral to the lesion, by over $98 \%$ in the caudate-putamen, $96 \%$ in the nucleus accumbens, and $65 \%$ in the frontal cortex as compared to the contralateral side (Table 3 ). In comparison with the right hemisphere in the nonlesioned control animals the decrease amounted to over $99 \%$ in the striatum, $96 \%$ in the nucleus accumbens, and $72 \%$ in the frontal cortex. There was a small reduction in DA levels also contralateral to the 6-OHDA lesion, which reached significance in the ventral caudate-putamen and in the frontal cortex. Consistent with previous results (Schmidt et al., 1983), the 6-OHDA lesion also produced reductions in striatal and cortical NA levels. 
A

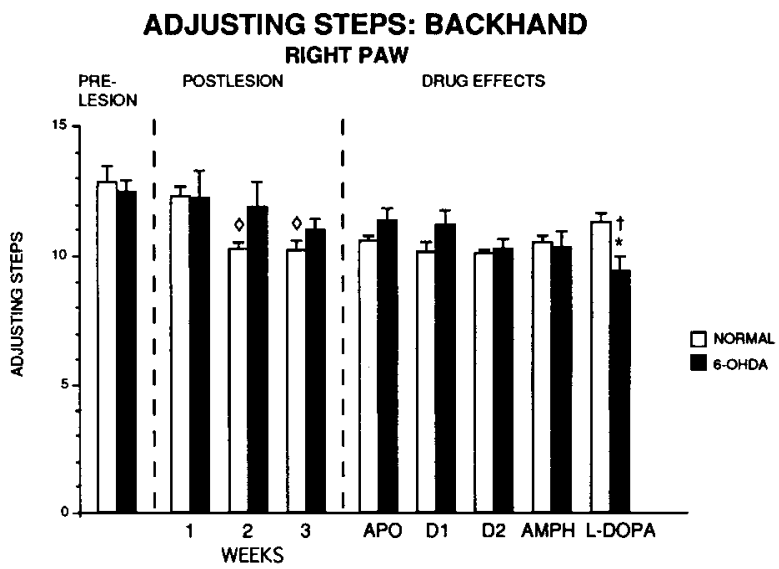

B

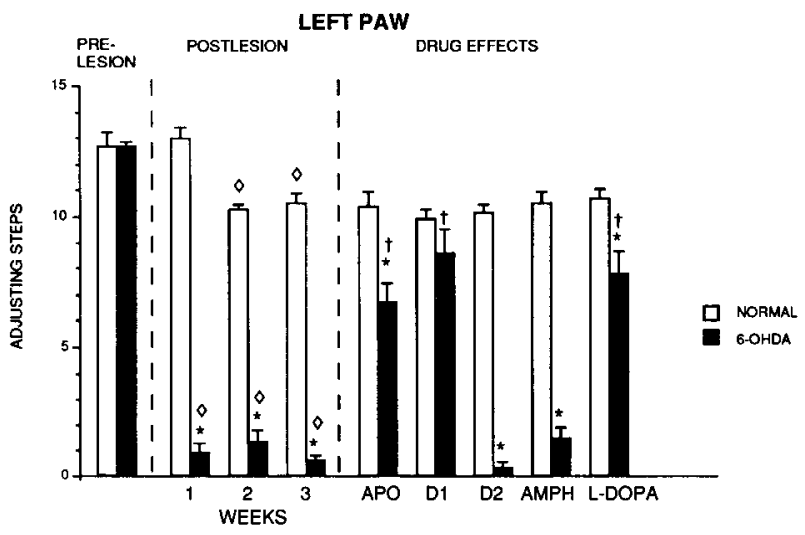

Figure 7. Expcriment 1: adjusting steps in the backhand direction for the right $(A)$ and the left $(B)$ paw. The performance of the left paw, which was severely impaired by the 6-OHDA lesion, was significantly improved by both apomorphine, SKF 38393 , and L- dopa $(B)$. *, significant difference between normal $(n=8)$ and 6-OHDA-lesioned groups $(N=8) ; \diamond$, significant difference compared to the prelesion test; $\dagger$, significant difference compared to the third postlesion test; 0.05 , one-factor ANOVA with Fisher post hoc test. Error bars represent SEM.

\section{EXPERIMENT 2. Effect of VM transplants in the 6-OHDA- lesioned rat}

\section{Stepping test}

Initiation time (Fig. 9A). All groups showed similar, short-latency initiation of movement with the right paw in all postgrafting test sessions (Fig. 9A, right). Initiation with the left paw (contralateral to lesion and graft) was significantly slower than with the right paw in the 6-OHDA lesion group, in both the 12 and 24 week tests, whereas the grafted animals did not show a significant left-right difference. The effect was most pronounced in the SN+CPU-grafted rats, which initiated movement more rapidly than the 6-OHDA lesion controls in the 24 week test ( $p$ $<0.05)$. The improvement was significant for both the $\mathrm{SN}+\mathrm{CPU}$ and the SN groups also in the 12 week test after logtransformation of the data (see Fig. $9 A$ ). Amphetamine treatment tended to improve left paw performance in the grafted groups but had no effect in the 6-OHDA lesion group. By contrast, apomorphine greatly innproved the initiation of movement in the 6- OHDA lesion group $(p<0.05)$. Also in the $\mathrm{SN}$ graft group
A

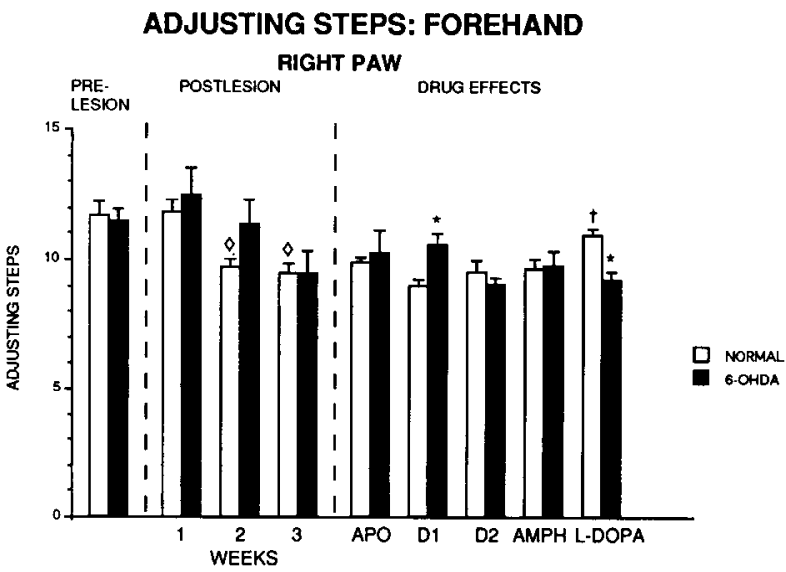

$\mathbf{B}$

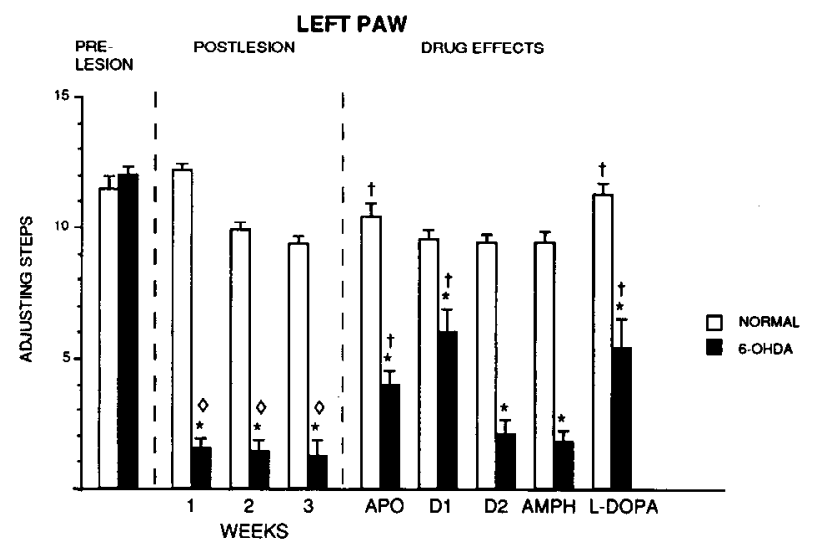

Figure 8. Experiment 1: adjusting steps in the forehand direction for the right $(A)$ and the left $(B)$ paw. The 6-OHDA lesion-induced deficits in the performance of the left paw $(B)$ were reversed by apomorphine, SKF 38393, and L-dopa, although to a lesser degree than in the backhand direction (Fig. 7). *, significant difference between normal $(n=$ $8)$ and 6-OIIDA-lesioned groups $(n=8) ; \diamond$, significant difference compared to the third prelesion test; $\dagger$, significant difference compared to the third postlesion test; $p<0.05$, one-factor ANOVA with Fisher hoc test. Error bars represent SEM.

there was a positive trend after apomorphine but this effect did not reach significance $(p=0.058)$.

Stepping time (Fig. 9B). Right paw stepping time was similar in all three groups (around $4 \mathrm{sec}$ ) in the no-drug tests, as well as after apomorphine. In the amphetamine test the rats in the $\mathrm{SN}+\mathrm{CPU}$ group moved significantly faster than the 6-OHDAlesioned controls $(p<0.05)$, and also faster than in the 24 week no-drug test $(p<0.01)$. Stepping time with the left paw (contralateral to lesion and graft) was significantly reduced in the SN+CPU graft group at both 12 and 24 weeks, and in the SN graft group at 24 weeks, compared to the 6-OHDA lesion controls $(p<0.05$ at 12 weeks; $p<0.005$ at 24 weeks; Fig. $9 B$ ). In the 24 week test stepping time for the left paw was no longer different from that of the right paw in either graft group. Amphetamine reduced left paw stepping time in the SN+CPU-grafted animals ( $p<0.01$ compared to the 24 week test) but had no effect in the lesion-only controls. There was a positive trend also in the SN graft group, but this did not reach significance. By contrast, apomorphine treatment resulted in a significant decrease in left paw stepping time in the 6-OHDA lesion group ( $p$ 
Table 2. Paw reaching performance with the left and the right paw in Iormal and unilaterally (right side) 6-OHDA-lesioned rats (experiment 1)

\begin{tabular}{|c|c|c|c|c|c|c|c|c|}
\hline & \multicolumn{2}{|l|}{ No drug } & \multicolumn{2}{|l|}{ Apomorphine } & \multicolumn{2}{|l|}{$\underline{\text { SKF } 38393}$} & \multicolumn{2}{|l|}{ Quinpirole } \\
\hline & Left & Right & Left & Right & Left & Right & Left & Right \\
\hline \multicolumn{9}{|l|}{ 6-OHDA lesion } \\
\hline Pellets taken & $\begin{array}{l}25.8^{* * * *} \\
( \pm 2.44)\end{array}$ & $\begin{array}{c}34.4 \\
( \pm 1.2)\end{array}$ & $\begin{array}{l}13.0^{* . * * . \dagger} \\
( \pm 4.1)\end{array}$ & $\begin{array}{c}31.9 \\
( \pm 2.5)\end{array}$ & $\begin{array}{l}10.1^{* * * *+\dagger} \\
( \pm 3.2)\end{array}$ & $\begin{array}{c}33.9 \\
( \pm 1.9)\end{array}$ & $\begin{array}{l}10.4^{* * * * \cdot \dagger} \\
( \pm 3.2)\end{array}$ & $\begin{array}{r}25.1 \dagger \\
( \pm 3.6)\end{array}$ \\
\hline \multicolumn{9}{|l|}{ Normal } \\
\hline Pellets eaten & $\begin{array}{c}31.2 \\
( \pm 0.7)\end{array}$ & $\begin{array}{c}30.1 \\
( \pm 1.0)\end{array}$ & $\begin{array}{r}25.8 \dagger \\
( \pm 2.2)\end{array}$ & $\begin{array}{r}26.3 \dagger \\
( \pm 2.3)\end{array}$ & $\begin{array}{c}31.0 \\
( \pm 1.7)\end{array}$ & $\begin{array}{c}29.2 \\
( \pm 2.4)\end{array}$ & $\begin{array}{r}19.3 \dagger \\
( \pm 3.0)\end{array}$ & $\begin{array}{r}20.0 \dagger \\
( \pm 3.0)\end{array}$ \\
\hline Pellets taken & $\begin{array}{c}38.1 \\
( \pm 0.6)\end{array}$ & $\begin{array}{c}36.8 \\
( \pm 1.2)\end{array}$ & $\begin{array}{c}34.3 \\
( \pm 2.2)\end{array}$ & $\begin{array}{c}33.7 \\
( \pm 2.3)\end{array}$ & $\begin{array}{c}38.0 \\
( \pm 0.9)\end{array}$ & $\begin{array}{c}35.7 \\
( \pm 2.1)\end{array}$ & $\begin{array}{r}26.7 \dagger \\
( \pm 3.5)\end{array}$ & $\begin{array}{r}26.9 \dagger \\
( \pm 3.7)\end{array}$ \\
\hline
\end{tabular}

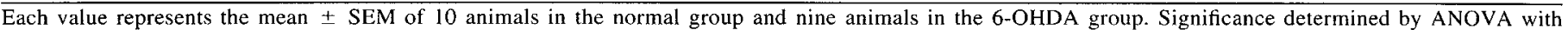
post hoc Fisher test. The No drug values represent the means of the 4 last days of testing, prior to drug challenge.

* Significant difference between the normal and the 6-OHDA group, $p<0.05$.

** Significant difference between the right and left side, $p<0.005$.

$\dagger$ Significant difference from the no drug testing, $p<0.05$.

$<0.01$ compared to the 24 week test), but had no effect in the grafted rats.

Step length (Fig. 9C). There were no differences between the groups in the right paw performance in any of the tests (Fig. $9 C$, right). With the left paw (Fig. 9C, left) step length was significantly increased in both graft groups at 12 weeks $(p<$ $0.001)$ and in the SN+CPU group also at 24 weeks $(p<0.01)$ compared to the 6-OHDA lesion group. The difference in step length between the lesioned and grafted animals was further accentuated after amphetamine $(p<0.001$ for both the SN and the $\mathrm{SN}+\mathrm{CPU}$ group). Comparison between the left and right paws showed that the 6-OHDA-lesioned animals generally stepped with shorter left paw steps (12 weeks, $p<0.005 ; 24$ weeks, $p<0.05$; amphetamine, $p<0.05$ ). These differences were, however, abolished by apomorphine. There were no significant right-left paw difference in the grafted animals, and apomorphine had no effect in these two groups.

Adjusting steps (Fig. 10). Right paw performance was similar in all three groups in both the backhand and the forehand directions and it was consistent over all test sessions (Fig. 10A, B, right). The lesion-induced deficit seen in the left paw, contralateral to the 6-OHDA lesion, was significantly counteracted both in the SN and in the SN+CPIJ graft groups when adjusting steps were tested in the backhand direction, at both 12 and 24 weeks postgrafting (Fig. 10A, left; $p<0.001$ ). Left paw performance was not markedly influenced by amphetamine in any of the groups. Apomorphine induced a marked increase in the number of adjusting steps in the backhand direction in the 6-OHDA lesion controls ( $p<0.001$ compared to the 24 week test), up to the level seen in the two graft groups, but had no effect in the grafted animals.

The graft effect on left paw performance was less pronounced in the forehand direction (Fig. 10B, left). A significant increase, compared to the lesion controls, was seen in the $\mathrm{SN}+\mathrm{CPU}$ group both at 12 and 24 weeks postgrafting $(p<0.005)$, whereas the SN graft group showed improved stepping only after amphet- amine $(p<0.005)$ or apomorphine $(p<0.01)$ treatment. Apomorphine, but not amphetamine, had a significant effect also in the 6-OHDA lesion control rats $(p<0.01)$, up to a level similar to that seen in the SN+CPU- grafted rats.

\section{Skilled forelimb use (paw reaching)}

'The rats studied in the stepping test were tested, at 14-15 weeks postgrafting, for skilled forelimb use in the same staircase test as used in experiment 1 . As shown in Table 4, the 6-OHDA lesion induced a marked deficit in the performance of the left paw, contralateral to the lesion $(p<0.05$ compared to the right paw for both numbers of pellets eaten and taken). No significant improvement in left paw performance was seen in any of the graft groups over the last $4 \mathrm{~d}$ of testing.

\section{Drug-induced rotation}

In the $\mathrm{SN}+\mathrm{CPU}$ group amphetamine-induced rotation was reduced from a mean of +10.3 turns $/ \mathrm{min}$ to $-0.3 \mathrm{turns} / \mathrm{min}$ (at 13 weeks) and -0.6 turns $/ \mathrm{min}$ (at 19 weeks) $(p<0.01$ in both cases), while the rate of rotation remained unchanged in the 6OHDA lesion only group as well as in the SN graft group. Apomorphine-induced rotation was significantly reduced in both graft groups: in the SN+CPU group by $42 \%(p<0.02)$ and in the SN group by $29 \%(p<0.05)$. Dl-agonist (SKF 38393)induced rotation was reduced by $96 \%$ in the $\mathrm{SN}+\mathrm{CPU}$ group ( $p$ $<0.01$ ) and by $75 \%$ in the SN graft group; D2-agonist (quinpirole)-induced rotation was reduced by $81 \%$ in the SN + CPU group ( $p<0.01$ ) and by $38 \%$ in the SN graft group. Due to one animal that exhibited low rate of rotation in response to the D1 and D2 agonists pretransplantation, the changes in D1-/and D2induced rotation did not reach significance in the $\mathrm{SN}$ graft group. These results, which are consistent with previous observations using the microtransplant technique (Nikkhah et al., 1993, 1994b), are indicative of good graft survival in both graft groups. 
Table 3. Regional dopamine and noradrenaline levels (pmol/mg wet weight) in normal and unilaterally (right side) 6-OHDA-lesioned brains (experiment 1)

\begin{tabular}{|c|c|c|c|c|c|c|c|c|}
\hline & \multicolumn{4}{|l|}{ Normal } & \multicolumn{4}{|c|}{ 6-OHDA lesion } \\
\hline & \multicolumn{2}{|l|}{ Left side } & \multicolumn{2}{|c|}{ Right side } & \multicolumn{2}{|l|}{ Left side } & \multicolumn{2}{|l|}{ Right side } \\
\hline & $\mathrm{DA}$ & NA & $\mathrm{DA}$ & NA & $\mathrm{DA}$ & NA & $\overline{\mathrm{DA}}$ & $\mathrm{NA}$ \\
\hline Frontal cortex & $\begin{array}{c}0.48 \\
( \pm 0.03)\end{array}$ & $\begin{array}{c}1.43 \\
( \pm 0.06)\end{array}$ & $\begin{array}{r}0.42 \\
( \pm 0.02)\end{array}$ & $\begin{array}{c}1.46 \\
( \pm 0.06)\end{array}$ & $\begin{array}{r}0.34 \dagger \\
( \pm 0.04)\end{array}$ & $\begin{array}{r}0.82 \dagger \\
( \pm 0.12)\end{array}$ & $\begin{array}{c}0.12 * \ddagger \\
( \pm 0.02)\end{array}$ & $\begin{array}{c}0.05 * \ddagger \\
( \pm 0.01)\end{array}$ \\
\hline $\begin{array}{l}\text { Nucleus } \\
\text { accumbens }\end{array}$ & $\begin{array}{r}17.48 \\
( \pm 0.96)\end{array}$ & $\begin{array}{c}1.18 \\
( \pm 0.18)\end{array}$ & $\begin{array}{r}18.98 \\
( \pm 0.51)\end{array}$ & $\begin{array}{c}1.18 \\
( \pm 0.18)\end{array}$ & $\begin{array}{r}16.93 \\
( \pm 1.00)\end{array}$ & $\begin{array}{r}0.72 \dagger \\
( \pm 0.09)\end{array}$ & $\begin{array}{l}0.70 * \ddagger \\
( \pm 0.17)\end{array}$ & $\begin{array}{c}0.32 * \div \\
( \pm 0.06)\end{array}$ \\
\hline \multicolumn{9}{|c|}{ Caudate-putamen } \\
\hline Dorsal & $\begin{array}{r}3818 \\
( \pm 1.70)\end{array}$ & $\begin{array}{c}0.29 \\
( \pm 0.02)\end{array}$ & $\begin{array}{r}47.32 \\
( \pm 1.93)\end{array}$ & $\begin{array}{c}0.25 \\
( \pm 0.01)\end{array}$ & $\begin{array}{r}36.74 \\
( \pm 1.45)\end{array}$ & $\begin{array}{c}0.28 \\
( \pm 0.02)\end{array}$ & $\begin{array}{r}0.28 * \dagger \\
( \pm 0.22)\end{array}$ & $\begin{array}{l}0.04 *+ \\
( \pm 0.01)\end{array}$ \\
\hline Ventral & $\begin{array}{r}38.49 \\
( \pm 1.02)\end{array}$ & $\begin{array}{c}0.42 \\
( \pm 0.05)\end{array}$ & $\begin{array}{r}37.71 \\
( \pm 1.53)\end{array}$ & $\begin{array}{c}0.44 \\
( \pm 0.03)\end{array}$ & $\begin{array}{r}32.52 \dagger \\
( \pm 1.16)\end{array}$ & $\begin{array}{c}0.33 \\
( \pm 0.04)\end{array}$ & $\begin{array}{c}0.42^{*} \ddagger \\
( \pm 0.28)\end{array}$ & $\begin{array}{c}0.03 *+ \\
( \pm 0.01)\end{array}$ \\
\hline
\end{tabular}

Each value represents the mean \pm SEM of eight animals. Significance determined by ANOVA with post hoc Fisher test.

* Significant difference between the right and the left side, DA $p<0.001$, NA $p<0.01$.

+ Significant difference between the left sides in the normal and the 6-OHDA group, $p<0.05$.

\# Significant difference between the right sides in the normal and the 6-OHDA group, DA $p=0.001, \mathrm{NA} p<0.001$.

\section{TH immunohistochemistry}

All animals in the $\mathrm{SN}$ and $\mathrm{SN}+\mathrm{CPU}$ groups had well-surviving grafts. Their size and general morphological appearance, as well as TH-positive cell survival and fiber outgrowth, were similar to those reported previously using the same grafting procedure (Nikkhah et al., 1994a,b). Detailed morphological results, using in situ hybridization histochemistry, will be reported separately (Bentlage et al., unpublished observations).

\section{Discussion}

Consistent with the previous observations of Norton et al. (1992) and Schallert et al. (1992), the 6-OHDA lesion induced marked long-lasting deficits in forelimb stepping on the side contralateral to the lesion, while the changes on the ipsilateral side were more subtle. The most pronounced effects were seen on two parameters. First, the time to initiate stepping by the affected limb was increased from 1-2 sec in normal animals to over $100 \mathrm{sec}$ in the 6-OHDA- lesioned rats. Second, the initiation of adjusting steps, when the affected limb was moved sideways along and in contact with the bench surface, was reduced by $80-90 \%$. Small changes were seen in these parameters also on the ipsilateral side, but they were transient and disappeared with further training. In addition, step length was reduced by about $30 \%$ and the time taken to step up a given distance along the ramp was increased by about $100 \%$. Changes in these latter parameters were significant also on the ipsilateral side, although the effect was smaller in magnitude. These deficits were evident also when the rats were trained on the task after the 6-OHDA lesion (experiment 2 ), although the lesioned animals required prolonged training to perform well and to reach asymptotic performance on the side ipsilateral to the lesion. The long-term deficits seen in the 6-OHDA-lesioned rats in experiment 2 tended to be smaller in magnitude and were somewhat more variable than in experiment 1, where the rats were trained to performance prior to lesion surgery.

\section{Aspects on the performance of the stepping test}

Similar to other motor initiation tests commonly used in rodents, such as the sensorimotor test of Marshall and Teitelbaum (1974) and the disengage test of Schallert and Hall (1988), the stepping test requires direct interaction between the experimenter and the animal. This introduces an inevitable subjective element into the test that may make it difficult to compare the results obtained by different experimenters. Strain differences as well as differences in the lest conditions, in addition, are known to influence greatly the rats' performance in these kinds of interactive tests. To obtain consistent results it is important, therefore, to standardize the test condition as far as possible with respect to the handling of the rats, the test procedure, the conditions in the test room, time of day of testing, and so on. During the stepping test the rat is held and one forelimb is restrained by the experimenter, which is potentially stressful. For this reason it is essential that the rat is allowed to habituate to the handling and the test grip during the training period that precedes the actual test. This requires patience, experience and skill on the part of the experimenter, and it is essential that all tests in an experimental series are carried out by the same experienced experimenter.

The experience gained from the use of the stepping test in our laboratory indicate that not all parameters of the test are equally reliable. The backhand and forehand adjusting steps appear to be a quite consistent measure across test sessions and from one experimenter to another, whereas both the initiation time and the stepping time measures have been more variable and observer dependent. These measures are clearly more susceptible to stress as well as to inexperience and impatience of the experimenter. In addition, we have found that the performance of the rats may be quite different between different breeders' stocks of animals. Using a different stock of Sprague-Dawley rats we have, for example, observed a more pronounced learning effect during extended testing than in the rats used here. For those who want to adopt the stepping test it is clearly advisable to make sure that the rats under investigation can acquire good, stable performance in the task before the experiments are initiated. For more objective assessment of initiation time and step length, in particular, the use of a video monitoring system may also be considered.

\section{Effects of DA agonist drugs}

In the 6-OHDA-lesioned animals low doses of the D1 agonist SKF $38393(2 \mathrm{mg} / \mathrm{kg})$ and the mixed D1 and D2-agonist apo- 
A

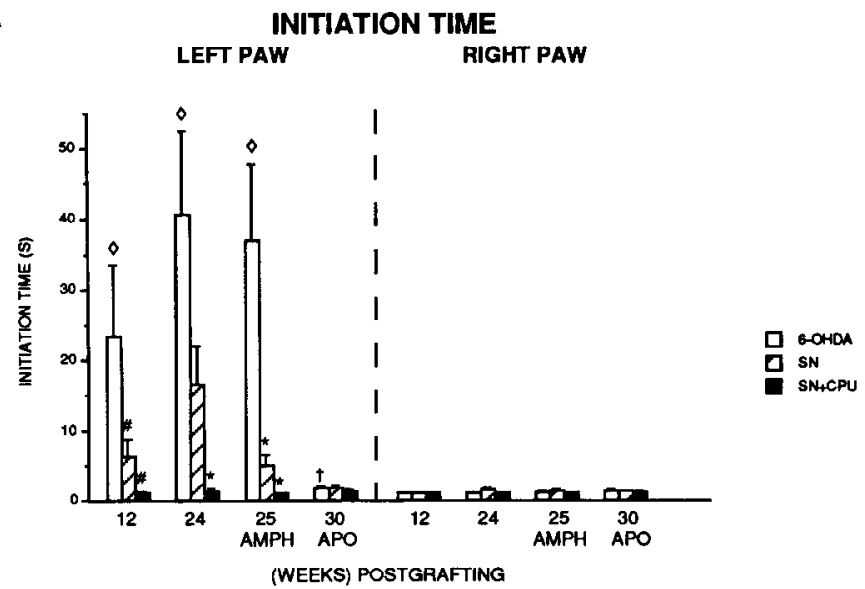

B
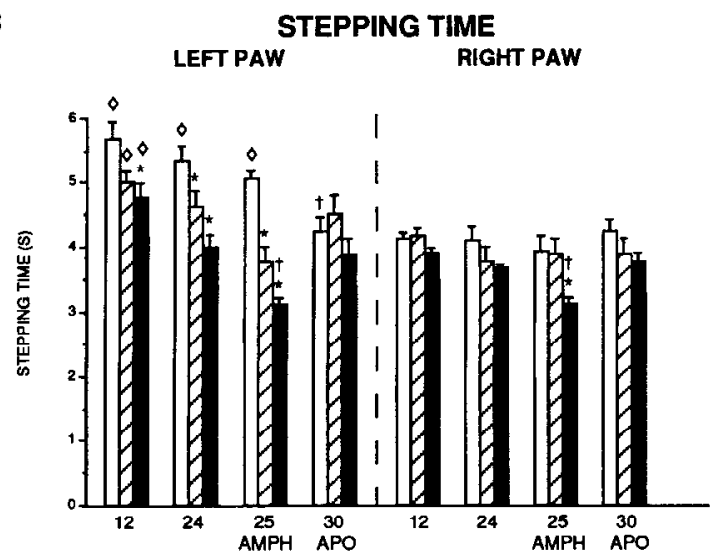

(WEEKS) POSTGRAFTING

C

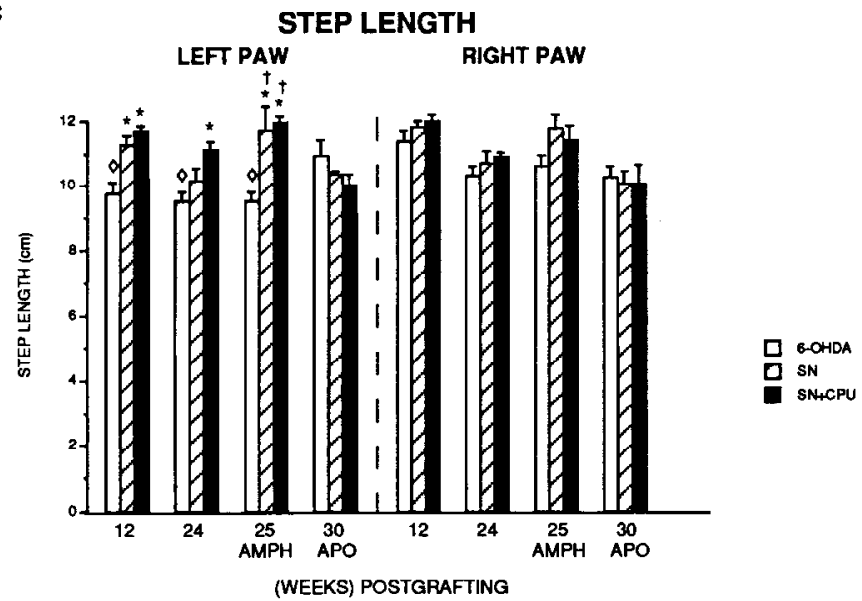

Figure 9. Experiment 2: initiation time $(A)$, stepping time $(B)$, and step length $(C)$ for the left and right paws. The animals were tested at 12 and 24 weeks postgrafting in the absence of drugs, and at 25 weeks after injection of $d$-amphetamine ( $A M P H ; 0.05 \mathrm{mg} / \mathrm{kg}$, i.p.), and 30 at weeks after injection of apomorphine $(A P O ; 0.0125 \mathrm{mg} / \mathrm{kg}$ in L-ascorbate-saline; s.c.). 6-OIIDA, 6-OIIDA-lesioned group; $S N$, 6-OHDA lesion followed by intranigral VM grafts; $S N+C P U$, 6-OHDA lesion followed by VM grafts in both SN and CPU. The 6-OHDA-induced impairment in left paw performance was reversed in the $\mathrm{SN}+\mathrm{CPU}$ group and partly reversed in the SN group. The graft-induced effects were further increased after amphetamine treatment. Apomorphine reversed the left paw impairment in the 6-OHDA group, but had no detectable effect in the grafted animals. *, significant difference compared morphine $(0.0125 \mathrm{mg} / \mathrm{kg})$ had significant effects on the akinesia of the contralateral paw: initiation time was almost normalized and the reduced step length and the impaired initiation of adjusting steps were partially reversed. L-Dopa $(10 \mathrm{mg} / \mathrm{kg})$ had similar effects, while the D2 agonist quinpirole $(0.05 \mathrm{mg} / \mathrm{kg})$ was clearly less effective. Amphetamine $(0.05 \mathrm{mg} / \mathrm{kg})$, which acts through release of endogenous DA, was without effect. The different dosages used were optimal in the sense that they were selected, in a pretest, to be just below the dose level of each drug that induced rotation. Thus, higher doses than those used here would not be compatible with accurate assessment of forelimb stepping due to interference by the dyskinetic, stereotype turning behavior induced by the higher doses.

Previous studies on locomotor behavior in rodents have shown that pharmacological activation of either D1 or D2 receptors can induce locomotion provided that the receptors are supersensitive (such as is the case 1-2 d after reserpine treatment in mice), whereas in conditions of normosensitive receptors combined activation of D1 and D2 receptors seems to be necessary (Gershanik et al., 1983; Ross et al., 1988; Pichler and Pifl, 1989). This is consistent with observations in unilaterally 6-OHDA-lesioned rats where rotation (which is due to activation of supersensitive receptors) can be induced by stimulation of either D1 or D2 receptors alone (Gershanik et al., 1983; Herrera-Marschitz and Ungerstedt, 1984; Fletcher and Starr, 1987; LaHoste and Marshall, 1990; Paul et al., 1992). In both cases, induction of locomotion (in the reserpinized mouse) and induction of rotation (in 6-OHDA-lesioned rats), D1 and D2 agonists have a clear synergistic effect (Ross et al., 1988; Pichler and Pifl, 1989; Paul et al., 1992; Robertson, 1992b). In the present study the effect of the D1 selective agonist on forelimb stepping was similar in magnitude to that obtained either with the mixed D1/D2 agonist apomorphine, or with L-dopa, which acts on both receptor subtypes, whereas the D2 agonist was clearly less effective at the present dose. The relative efficacy of the difference drugs in the stepping test is interestingly similar to that seen on rotation (after higher doses of the drug), where the effect of quinpirole is clearly less than that of SKF 38393 or aponorphine (Rioux et al., 1991; Robertson, 1992b; Nikkhah et al., 1993). However, while the low-dose effects on stepping appears as a normalization of initiation of limb movements, the rotational response can be viewed as a dyskinetic response associated with overstimulation of the supersensitive DA receptors. In this context it should be noted that there are species differences in relative effects of D1-/and D2-selective agonists on parameters of akinesia. Thus, in both MPTP-treated monkeys and Parkinsonian patients Dl agonists alone have no or only weak effects on general motor activity or bradykinesia, although D1 agonists, at least in MPTP-treated monkeys, appear to potentiate the antibradykinetic action of D2-selective agonists (Nomoto et al,, 1985; Emre et al., 1992; Gomez-Mancilla et al., 1993).

\section{Effects of VM transplants}

In experiment 2 the VM transplants in the SN । CPU group reversed akinesia in the contralateral paw to the same degree as

to the lesion-only control group, $\diamond$, significant difference between right and left paw; $\uparrow$, significant difference between either amphetamine or apomorphine and the 24 week predrug test; $p<0.05$, one-factor ANOVA, Fisher post hoc test. Error bars represent SEM. \#, significant from 6-OHDA lesion only after log-transformation of the data. 
A

\section{ADJUSTING STEPS: BACKHAND \\ LEFT PAW \\ RIGHT PAW}

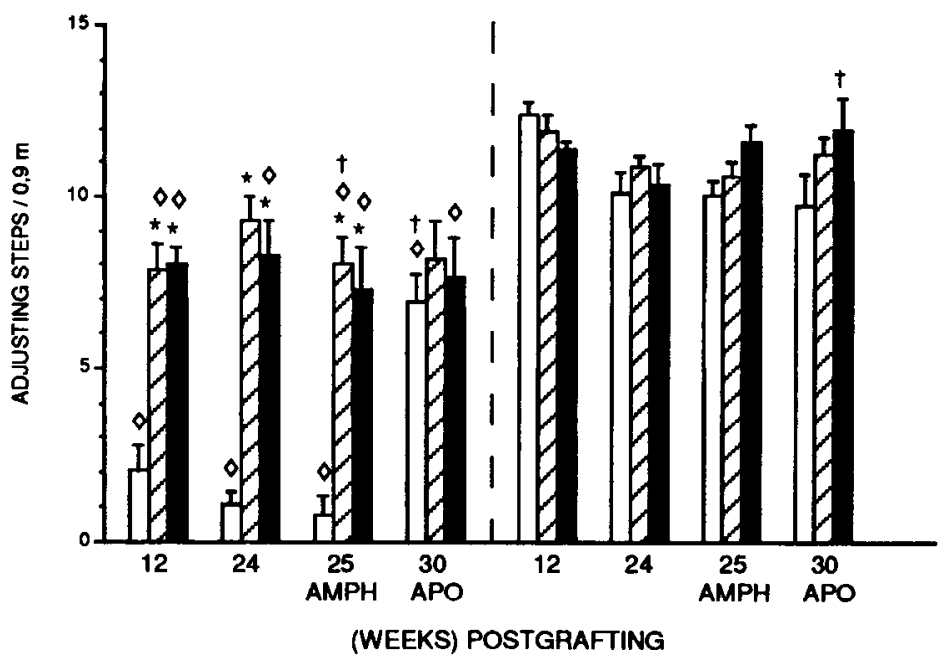

B

\section{ADJUSTING STEPS: FOREHAND \\ LEFT PAW RIGHT PAW}

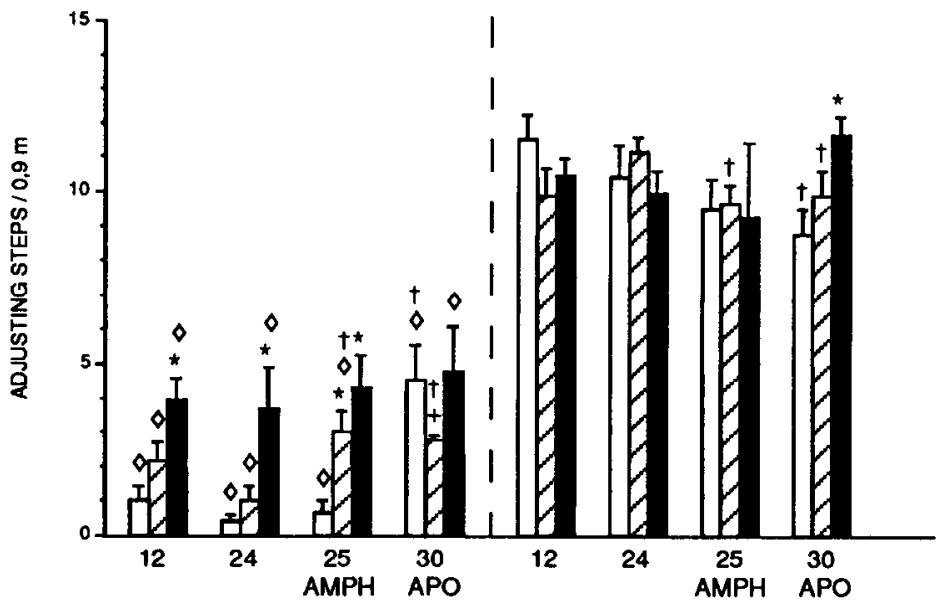

(WEEKS) POSTGRAFTING
口 6-OHDA

D $\mathrm{SN}$

SN+CPU
D 6-OMDA

D $\mathrm{SN}$

SN+CPU

Table 4. Paw reaching performance in the three groups of rats in experiment 2, 14-15 weeks postgrafting: 6-OHDA lesion only, 6-OHDA lesion plus SN graft (SN), and 6-OHDA lesion plus SN and CPU graft (SN + CPU)

\begin{tabular}{|c|c|c|c|c|c|c|}
\hline & \multicolumn{2}{|l|}{ 6-OHD $\Lambda$} & \multicolumn{2}{|l|}{ SN graft } & \multicolumn{2}{|c|}{$\mathrm{SN}+\mathrm{CPU}$ graft } \\
\hline & Left paw & Right paw & Left paw & Right paw & Left paw & Right paw \\
\hline \multirow[t]{2}{*}{ Pellets eaten } & $9.4^{*}$ & 26.3 & $8.1^{*}$ & 27.5 & $9.2 *$ & 23.1 \\
\hline & $( \pm 2.9)$ & $( \pm 2.0)$ & $( \pm 3.2)$ & $( \pm 2.0)$ & $( \pm 2.8)$ & $( \pm 3.0)$ \\
\hline \multirow[t]{2}{*}{ Pellets taken } & $20.0 *$ & 35.8 & $20.1 *$ & 38.3 & 22.2 & 32.8 \\
\hline & $( \pm 3.2)$ & $( \pm 1.2)$ & $( \pm 4.6)$ & $( \pm 1.0)$ & $( \pm 3.6)$ & $( \pm 2.0)$ \\
\hline \multirow[t]{2}{*}{$\%$ Success } & $40.1^{*}$ & 72.7 & $36.7^{*}$ & 71.6 & $36.9^{*}$ & 69.3 \\
\hline & $( \pm 6.6)$ & $( \pm 3.4)$ & $( \pm 11.2)$ & $( \pm 3.7)$ & $( \pm 5.8)$ & $( \pm 6.3)$ \\
\hline
\end{tabular}

The rats were lesioned and grafted on the right side. Each value represents the mean \pm SEM of the last 4 test days for eight animals in the 6-OHDA group and seven animals in the SN + CPU group.

* Significant difference between the right and the left side, $p<0.05$, ANOVA with post hoc Fisher test.

Figure 10. Experiment 2: adjusting steps in the backhand $(A)$ and in the forehand $(B)$ direction for the left and right paws. The lesion-induced impairment in the left paw was reversed in the $\mathrm{SN}+\mathrm{CPU}$ group and partly reversed in the SN group. Left paw performance was further improved after amphetamine treatment in the $\mathrm{SN}$ group. Apomorphine reduced the left paw impairment in the 6-OHDA group without any detectable effect in the grafted animals. *, significant difference compared to lesion-only control group; $\diamond$, significant difference between right and left paw; + , significant difference between either amphetamine or apomorphine and the 24 week predrug test; $p<0.05$, one-factor ANOVA, with Fisher post hoc test. Error bars represent SEM. 
apomorphine: initiation time and step length were normalized and the defect in initiation of adjusting steps was reduced by $40-80 \%$. Interestingly, grafts implanted into the substantia nigra alone (SN group) had a significant, though partial, effect on all four parameters and this effect was further improved by a low dose of amphetamine or apomorphine. Indeed, in combination with either drug the performance of the rats with intranigral VM grafts was similar to that seen in rats with grafts in both SN and CPU. By contrast, no additive effect of amphetamine or apomorphine was seen in the rats with grafts in both striatum and substantia nigra. These results are consistent with previous pharmacological data showing that the effects of DA agonist drugs on motor behavior are mediated via DA receptors located in both striatum and substantia nigra (Robertson and Robertson, 1989; LaHoste and Marshall, 1990; Robertson, 1992a). Although the number of rats in the SN graft group was small $(n=4)$, these data indicate that $\mathrm{DA}$ - releasing grafts placed within the substantia nigra can improve spontaneous motor performance in the 6-OHDA-lesioned rat and that the effect on forelimb akinesia by intrastriatal and intranigral VM transplants may be additive. This is supported by preliminary observations on 6-OHDA-lesioned rats with intrastriatal nigral grafts only (Olsson et al., unpublished observations) indicating an effect on forelimb stepping intermediate to the ones seen here.

Previous studies (Nikkhah et al., 1993, 1994b) have shown that intranigral VM transplants may be as effective as intrastriatal VM grafts in reducing DA agonist-induced rotation, induced by either apomorphine or selective D1-/and D2-receptor agonists, provided that the grafted DA neurons are distributed over both the anterior and posterior parts of the nucleus. Similar effects were observed in the present SN and SN+CPU grafts. Rotation in rats with unilateral 6-OHDA lesions is elicited by DA agonists in doses sufficiently low to activate only supersensitive receptors. Rotation is thus generally regarded as a behavioral correlate of DA receptor supersensitivity in the DA-denervated striatonigral system. Consistent with this view, it has been shown that the reduction in DA agonist-induced turning by intrastriatal VM transplants is accompanied by a normalization of DA receptor supersensitivity in the reinnervated striatum (Rioux et al., 1991; Dawson et al., 1991; Christin et al., 1992; Savasta et al., 1992) and the ipsilateral substantia nigra (Dawson et al., 1991), as assessed by ligand binding or in situ hybridization techniques. Indeed, Rioux et al. (1991) and Savasta et al. (1992) have reported parallel reductions in D1 and D2 agonists induced rotation and receptor ligand binding in rats with intrastriatal VM grafts, suggesting that the two parameters may be closely linked. With respect to intranigral VM grafts, the transplanted dopaminergic neurons have been seen to extend abundant $\mathrm{TH}$-positive processes (presumably dendrites) into the substantia nigra pars reticulata, but they do not establish any connections with the denervated striatum (Nikkhah et al., 1994b). Thus, the effects of intranigral VM grafts are likely to be due to DA rclcasc within the nigra itself. Since intranigral VM grafts can be as efficient, or almost as efficient, as intrastriatal grafts in reducing agonistinduced rotation it is suggested that intranigral DA release can normalize DA receptor supersensitivity not only in the substantia nigra itself, but also at the level of the cell bodies of the striatonigral neurons within the striatum (see Nikkhah et al., 1994b, for further discussion).

Importance of task complexity

From previous studies it is clear that intrastriatal VM grafts can induce complete recovery on, for example, motor asymmetry and simple sensorimotor orienting responses in 6-OHDA-lesioned rats, whereas deficits in more complex integrative behaviors such as skilled forelimb use in the paw-reaching test and more complex sensorimotor integration in the "disengage" test are more resistant to graft-induced functional improvement (Dunnett et al., 1987; Mandel et al., 1990; Nikkhah et al., 1993). These previous results have been obtained in 6-OHDA-lesioned rats with grafts confined to the denervated caudatc- putamen. A similar pattern of recovery, however, was seen in the present animals, where the VM grafts had been placed into both striatum and substantia nigra, or into the substantia nigra alone, which suggests that the SN graft placement does not contribute any further improvement in the more complex paw-reaching task. The comparison between stepping and paw reaching studied here, is particularly instructive in this regard since both tasks involve tests of forelimb movement. Interestingly, the same doses of DA agonists that induced marked improvement in forelimb stepping had no observable effect on the paw- reaching deficit. Indeed, in the transplant experiment the effect of apomorphine and VM transplants were closely matched: the ability of a supersensitive dose of apomorphine to improve stepping, which was pronounced in the lesion-only animals, was reduced in the rats with intranigral grafts and totally abolished in the combined SN+CPU group. Notably, the level of performance in the stepping test was similar in the $\mathrm{SN}+\mathrm{CPU}$-grafted animals and in the lesion-only (and SN-grafted) animals under apomorphine stimulation. Paw reaching, which involves a more complex sequence of coordinated goal- directed movements (reaching, grasping, manipulation, and retrieval), is, by contrast, clearly less responsive to either DA receptor activation or DA rich transplants.

In conclusion, the present observations strongly suggest that the graft-induced effects on rotation and forelimb akinesia may have similar underlying mechanisms, that is, tonic activation of DA receptors in striatum and/or substantia nigra by a sustained release of DA from the grafted dopaminergic neurons, which results in a normalization of the sensitivity of the initially denervated receptors. However, in comparison with the standard rotation test, which monitors a hyperkinetic or stereotype motor behavior in response to activation of supersensitive DA receptors, the stepping test provides a more direct measure of the underlying motor deficit, analogous to limb akinesia seen in human PD. The deficits in skilled paw reaching, by contrast, appear to depend on more complex integrative mechanisms that are clearly less responsive to either DA receptor activation or VM transplants. The stepping test should thus provide a highly useful tool for more detailed analysis of the functional efficacy of neural transplants and other DA substitution strategies in the rat PD model.

\section{References}

Dawson TM, Dawson VL, Gage FH, Fisher LJ, Hunt MA, Wamsley JK (1991) Functional recovery of supersensitive dopamine receptors after intrastriatal grafts of fetal substantia nigra. Exp Neurol 111:282292.

Dunnett SB, Iversen SD (1982) Sensorimotor impairments following localized kainic acid and 6-hydroxydopamine lesions of the neostriatum. Brain Res 248:121-127.

Dunnett SB, Robbins TW (1992) The functional role of mesotelencephalic dopamine systems. Biol Rev 67:491-518.

Dunnett SB, Whishaw IQ, Rogers DC, Jones GH (1987) Dopaminerich grafts ameliorate whole body motor asymmetry and sensory neglect but not independent limb use in rats with 6-hydroxydopamine lesions. Brain Res 415:63-78.

Emre M, Rinne UK, Rascol A, Lees A, Agid Y, Lataste X (1992) 
Effects of a selective partial D1 agonist, CY 208-243, in de novo patients with Parkinson's disease. Movement Disord 7:239-243.

Fletcher GH, Starr S (1987) Role of the substantia nigra in the expression of dopamine D1 receptor-mediated and D2 receptor-mediated behaviours. Neuroscience 23:1001-1010.

Gershanik O, Heikkila RE, Duvoisin RC (1983) Behavioral correlations of dopamine-receptor activation. Neurology 33:1489-1492.

Gomez-Mancilla B, Boucher R, Gagnon C, Di Paolo, T, Markstein R, Bédard PJ (1993) Effect of adding the D1 agonist CY 208-243 to chronic bromocriptine treatment. I: Evaluation of motor parameters in relation to striatal catecholamine content and dopamine receptors. Movement Disord 8:144-150.

Herrera-Marschitz M, Ungerstedt U (1984) Evidence that apomorphine and pergolide induce rotation in rats by different actions on D1 and D2 receptor sites. Eur J Pharmacol 98:165-176.

LaHoste GJ, Marshall JF (1990) Nigral D1 and striatal D2 receptors mediate the behavioral effects of dopamine agonists. Behav Brain Res 38:233-242.

Mandel RJ, Brundin P, Björklund A (1990) The importance of graft placement and task complexity for transplant-induced recovery of simple and complex sensorimotor deficits in dopamine denervated rats. Eur J Neurosci 2:888-894.

Marshall JF, Teitelbaum P (1974) Further analysis of sensory inattention following lateral hypothalamic damage in the rat. J Comp Physiol Psychol 86:375-395.

Montoya CP, Campbell HL, Pemberton KD, Dunnett SB (1991) The 'staircase test': a measure of independent forelimb reaching and grasping abilities in rats. $J$ Neurosci Methods 36:2-3.

Nikkhah G, Duan W-M, Knappe U, Jödicke A, Björklund A (1993) Restoration of complex sensorimotor behavior and skilled forelimb use by a modified nigral cell suspension transplantation approach in the rat Parkinson model. Neuroscience 56:33-43.

Nikkhah G, Cunningham MG, Jödicke A, Knappe U, Björklund A (1994a) Improved graft survival and striatal reinnervation by microtransplantation of fetal nigral cell suspensions in the rat Parkinson model. Brain Res 633:133-143.

Nikkhah G, Bentlage C, Cunningham MG, Björklund A (1994b) Intranigral fetal dopamine grafts induce behavioral compensation in the rat Parkinson model. J Neurosci 14:3449-3461.

Nomoto M, Jenner P, Marsden CD (1985) The dopamine D2 agonist LY 141865, but not the D1 agonist SKF 38393, reverses Parkinsonism induced by 1-methyl-4- phenyl-1,2,3,6-tetrahydropyridine (MPTP) in the common marmoset. Neurosci Lett 57:37-41

Norton D, Schallert T, Jones TA (1992) Akinesia during dopamine agonist induced circling behavior after severe unilateral neostriatal dopamine depletion in rats. Soc Neurosci Abstr 18:451.5.

Paul ML, Graybiel AM, David JC, Robertson HA (1992) D1-like and D2-like dopamine receptors synergistically activate rotation and c- fos expression in the dopamine-depleted striatum in a rat model of Parkinson's disease. J Neurosci 12:3729-3742.

Pichler L, Pifl CH (1989) Locomotor behaviour of selective dopamine agonists in mice: is endogenous dopamine the only catecholamine involved? J Pharm Pharmacol 41:690-693.

Rioux L, Gaudin DP, Cagnon C, Di PT, Bedard PJ (1991) Decrease of behavioral and biochemical denervation supersensitivity of rat striatum by nigral transplants. Neuroscience 44:75-83.

Robertson GS, Robertson HA (1989) Evidence that L-dopa-induced rotational behavior is dependent on both striatal and nigral mechanisms. J Neurosci 9:3326-3331.

Robertson HA (1992a) Dopamine receptor interactions: some implications for the treatment of Parkinson's disease. Trends Neurosci 15: 201-206.

Robertson HA (1992b) Synergistic interactions of D1-/and D2-selective dopamine agonists in animal models for Parkinson's disease: sites of action and implications for the pathogenesis of dyskinesias. Can J Neurol Sci 19:147-152.

Ross SB, Jackson DM, Wallis EM, Edwards SR (1988) Enhancement by a single dose of reserpine (plus alpha methyl-p-tyrosine) of the central stimulatory effects evoked by dopamine D1 and D2 agonists in the mouse. Naunyn Schmiedebergs Arch Pharmacol 337:512-518.

Savasta M, Mennicken F, Chritin M, Abrous DN, Feuerstein C, Le MM, Herman JP (1992) Intrastriatal dopamine-rich implants reverse the changes in dopamine D-2 receptor densities caused by 6-hydroxydopamine lesion of the nigrostriatal pathway in rats: an autoradiographic study. Neuroscience 46:729-738.

Schallert T, Hall S (1988) Disengage sensorimotor deficit following apparent recovery from unilateral dopamine depletion. Behav Brain Res 30:15-24.

Schallert T, Norton D, Jones TA (1992) A clinically relevant unilateral rat model of Parkinsonian akinesia. J Neural Transpl Plast 3:332333.

Schmidt RH, Björklund A, Lindvall O, Stenevi U, Björklund A (1982) Functional activity of substantia nigra grafts reinnervating the striatum: neurotransmitter metabolism and ${ }^{14} \mathrm{C}$-2-deoxy-D- glucose autoradiography. J Neurochem 38:737-748.

Schmidt RH, Björklund A, Stenevi U, Dunnett SB, Gage FH (1983) Intracerebral grafting of neuronal cell suspension. III. Activity of intrastriatal nigral suspension implants as assessed by measurements of dopamine synthesis and metabolism. Acta Physiol Scand [Suppl] 522: 19-28.

Ungerstedt U, Arbuthnott G (1970) Quantitative recording of rotational behavior in rats after 6-hydroxy-dopamine lesions of the nigrostriatal dopamine system. Brain Res 24:485-493.

Whishaw IQ, O'Connor WT, Dunnett SB (1986) The contributions of motor cortex, nigrostriatal dopamine and caudate-putamen to skilled forelimb use in the rat. Brain 199:805-843. 